brass rods threaded at the ends and provided with nuts. The ends of the tubes are closed by glass plugs, wired in ; in order to keep the rubber from tearing, a wedge-shaped piece of cork is inserted at each end, as shown by the dotted lines in the figure.

The capacity of the pump is $500 \mathrm{cc}$. Three strokes are suffi-

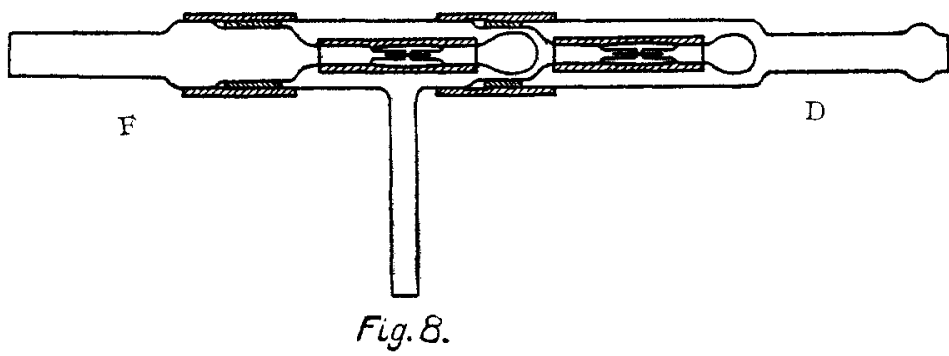

cient to attain the maximum pressure in the antimony sulphide experiment.

With this apparatus a gas can be brought to the pressure of the water system without coming into contact with any liquid. Higher pressure may be attained by using a force pump; the limit depends only on the strength of the apparatus and on the ratio between the variable volume (rubber tubing) and the constant volume (glass tubing) between the valves.

THE CHEMICAL LABORATORY OF THE CZNIVERSTIY OF TORONTO, April, IgOO.

[CONTRIBUTIONS FROM THE HAVEMEYER LABORATURIES OF COLCMBIA UNIVERSITY, No. 23.]

\title{
A NEW ELECTROLYTIC CELL FOR RECTIFYING ALTERNATING CURRENTS.
}

BI W. L, HILDBURGH.

Received Aprí 3, 1900.

I $\mathrm{N}$ electrical work an automatic device which will permit a current to pass through it in one direction only is frequently desirable, for rectifying alternating currents, for example, or for preventing a back-flow of current due to polarization. In addition to mechanical commutators several arrangements for the purpose have been previously known, but, with one exception, they are applicable to comparatively high voltages only. This exception is the two-cell rectifier described by Prof. M. I. Pupin 
before the American Physical Society.' In the present paper a new class of electrolytic cells capable of affecting currents of extremely low voltage is described. These cells act by the production of a counter E, M. F. of polarization whose intensity depends on the direction of the E.M.F. impressed, and have been termed "Single Cell Rectifiers."

If a plate of copper be placed in dilute sulphuric acid it will not dissolve. If, however, a platinum electrode be placed in the acid, and the copper made the anode, a very small E. M. F. is sufficient to cause the copper to dissolve freely and hydrogen to be deposited on the platinum, and a current will pass until all the copper is carried into solution. When the source of the E.M.F. is reversed a momentary current passes, the platinum plate becomes covered with oxygen, and, if the impressed voltage is not too high, the current ceases almost completely. That is, the cell $\mathrm{Cu}\left|\mathrm{H}_{2} \mathrm{SO}_{4}\right| \mathrm{Pt}$, producing no current, permits the passage of continuous currents of low E. M. F. through it in one direction only.

By placing a number of such cells in series it is possible to prevent the flow of a current of any voltage whatsoever. Such a cell may be used for the rectification of alternating currents by so regulating the size of the platinum plate that the quantity of current necessary to polarize it as anode is less than that which passes during the next half-wave, when the platinum acts as cathode. The smaller the platinum, or passive plate, the higher the degree of rectification (asymmetrical efficiency) attainable. The amount of rectification is dependent, however, not only on the size of the passive plate, but also on the quantity of current which can pass; that is, on the current density at the surface of that plate. Consequently the lower the resistance in the circuit or the lower the frequency of the alternating E. M. F. impressed the greater will be the asymmetrical efficiency.

In the cell $\mathrm{Cu}\left|\mathrm{H}_{2} \mathrm{SO}_{4}\right| \mathrm{Pt}$, or more properly speaking, $\mathrm{Cu}\left|\mathrm{CuSO}_{4}\right| \mathrm{H}_{2} \mathrm{SO}_{4} \mid \mathrm{Pt}$, considerably more energy is required to produce hydrogen at the passive plate than is given out by the solution of the copper, or active plate. As this evidently lowers the efficiency of the device by producing an E. M. F.

1 June, I 899. 
counter to the main flow of current, means should be adopted of making the energy given out at the active plate and that absorbed at the passive as nearly equal as possible. By making the active plate of the substance given off at the passive plate by the current in the "useful" direction this condition can be nearly fulfilled. The substance produced at the passive plate should be a gas, as otherwise that electrode will soon become covered with a layer of active substance and cease to be inert. Gaseous active electrodes may be formed with hydrogen, oxygen, chlorine, etc., as the active material, absorbed by platinum or in chemical combination with some metal.

Of such electrodes the writer has found that hydrogen when absorbed by platinum black gives by far the best results, and can be made, in addition, self-regenerating, giving a "continuousacting" rectifier such as is shown in illustration. V is a sealed vessel into which pass two mercury-contact electrodes $A$ and $P$. $\mathrm{A}$, the active plate, is of platinized platinum, partly in hydrogen

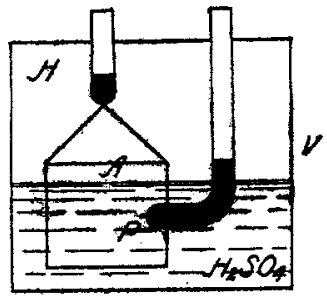

gas $(\mathrm{H})$ and partly in sulphuric acid $\left(\mathrm{H}_{2} \mathrm{SO}_{4}\right) . \quad \mathrm{P}$, the passive electrode, is a platinum wire sealed into glass and cut off to give the desired surface of contact with the liquid, or filed plane with the sealed end of the tube. The "useless" current carries oxygen to $P$, but is of insufficient voltage to produce bubbles, and the cell polarizes. In the opposite, or "useful" direction hydrogen is carried from $A$ to $P$, is there given off in bubbles, and goes back to join again the gas $H$. It is clear that since nothing but hydrogen is produced at $\mathrm{P}$, provided the impressed E. M. F. is not too high, that the cell will work for an indefinite time, or until changes in the surface of the platinum electrodes stop the actions described.

For the most perfect action of rectifiers of this class there 
should be no counter E. M.F. in the "useful" direction. In the hydrogen-cell it requires from a few thousandths of a volt to 0.085 volt to carry the gas through the electrolyte, the pressure varying with the size of the passive electrode and the condition of its surface, the concentration of the liquid, the temperature, etc. This counter E. M. F. can be "balanced," as is necessary for certain kinds of work, by adding an E. M. F. in the "useful" direction, taken from a slide-wire in series with $I$ or 2 cells of battery.

It is impossible to specify the size of the various parts of a cell without knowing all the conditions under which it is to be used. As a general rule the small (passive) electrode should be of the dimensions of a millimeter, ranging in area from a small fraction of I sq. mm. up to Ioo sq. mm., according to the frequency and the resistance or inductance in the external circuit. The platinized electrode should be of sufficient size to absorb hydrogen as fast as it is given off at the passive plate. For the electrolyte I part sulphuric acid to about 8 or Io of distilled water, from which the oxygen has been removed by boiling or exhaustion, serves very well. The vessel need only be large enough to contain the two electrodes and a little liquid and gas, the latter two being employed continuously, and only a very small quantity being in use at any one time. The larger electrode should be thoroughly washed after platinizing, as otherwise platinum may be carried to the smaller electrode, impairing the efficiency. A jar of water, in which the cell may be kept, offers a convenient method of sealing, for laboratory use.

The following points will be found of service in working with the cell, and have been obtained, for the most part, by the study of curves taken with alternating currents. More complete expositions of the theory and actions of rectifiers of this class will be found in other papers by the writer.'

The smaller the plates the greater the asymmetrical efficiency.

The greater the resistance in the circuit the less the asymmetrical efficiency.

The higher the frequency the less the asymmetrical efficiency.

The higher the frequency, or the greater the resistance, or the larger the plates, the higher may be the impressed alternating

1 Elec. World and Eng., t900; School of Mines Quarterly, July and Oct., I900. 
E. M.F. in a given cell, without producing oxygen bubbles at the smaller plates.

In a perfectly "balanced" rectifier, as long as the impressed E. M. F. is not too high, the quantity of current capable of doing unidirectional work is proportional to the impressed E. M. F.

If the active $E . M . F$. of a rectifier be too high a continuous current will flow, and the amount of rectification be dependent on the impressed E. M. F.; if the latter below, rectification may cease completely.

If the active E. M. F, be too low the amount of rectification is dependent on the impressed F.M.F., and may become zero if the latter be low. This property prevents the use of rectifiers in circuits in which any considerable counter E. M.F. is produced.

Rectifiers for high E. M. F. can be formed by joining a number of cells in series. The passive plates in each can then be correspondingly increased in size, while the whole set gives the same efficiency as one of the cells gave before its electrode was enlarged. The number of rectifiers and the impressed E. M. F. should be proportioned to their circuit exactly as primary cells are proportioned, each primary cell being represented by a rectifier and a certain portion of the impressed E. M. F.

[CONTRIBUTIONS FROM THE HAVEMEYER IABOKATORIES OF COLUMBIA [NIVERSITY, No. 24.]

\section{A METHOD FOR THE DETERMINATION OF ELECTRI- CAL CONDUCTIVITY WITH DIRECT CURRENT INSTRUMENTS.}

By J. Iivingston R. Morgan and W. I. HILdblRgh.

Received Apri1 3,1900.

I the determination of electrical conductivity, in order 10 pre1 vent errors, it is necessary to use an alternating current whose frequency is of such a value that the electrodes, during a half period of the alternating current, receive a polarization which is negligible compared to the voltage impressed. Up to the present time it has been difficult to detect small quantities of an alternating current, except by aid of the telephone. In the 